\title{
ORIGINAL ARTICLE \\ Optimization of the mean arterial pressure and timing of surgical decompression in traumatic spinal cord injury: a retrospective study
}

\author{
A Dakson, D Brandman, G Thibault-Halman and SD Christie
}

Study design: A retrospective comparative study.

Objectives: This study aims to investigate the extent to which early surgical decompression and maintenance of MAP $\geqslant 85 \mathrm{~mm} \mathrm{Hg}$ for 5 days postinjury affected neurological recovery utilizing internal controls for comparison of outcomes in patients with traumatic spinal cord injury.

Setting: Acute trauma center, Halifax, Nova Scotia, Canada.

Methods: We identified 94 cases of traumatic SCI. Follow-up data were available at an average of 26.7 $\pm 19.5,115.0 \pm 69.3$, and $252.0 \pm 152.8$ days postinjury for 61,48 , and 47 patients, respectively. Neurological recovery was assessed using the American Spinal Cord Injury Association (ASIA) Impairment Scale (AIS).

Results: Patients with MAP $<85 \mathrm{~mm} \mathrm{Hg}$ for at least 2 consecutive hours during the 5-day period postinjury were 11 times less likely to have an improvement in the AIS grade when compared with patients with MAP $\geqslant 85 \mathrm{~mm} \mathrm{Hg}(P=0.006)$. This association was independent of early surgery or the severity of SCl. At a mean of 252.0 days postinjury, a significantly greater proportion of $\mathrm{SCl}$ patients treated with early surgical decompression (within $24 \mathrm{~h}$ ) improved neurologically $(P=0.031)$.

Conclusions: Our data demonstrated that there may be improved neurologic outcomes in patients with $\mathrm{SCI}$ who undergo early surgical decompression. Maintenance of MAP $\geqslant 85 \mathrm{~mm} \mathrm{Hg}$ for 5 consecutive days post-SCl was also associated with higher rates of AIS grade improvement at mean 26.7 days without a statistically significance difference at prolonged follow-up although a higher rate of neurological recovery persisted in patients with MAP $\geqslant 85 \mathrm{~mm} \mathrm{Hg}$.

Spinal Cord (2017) 55, 1033-1038; doi:10.1038/sc.2017.52; published online 20 June 2017

\section{INTRODUCTION}

Traumatic spinal cord injuries (SCI) have a substantial economic and social impact on society. ${ }^{1,2}$ There are about 250000 individuals currently living with SCI in North America, with an annual incidence of 28-55 cases per million people. ${ }^{3}$ The lifetime cost estimates are on the order of $\$ 500000$ to $\$ 2$ million per individual, amounting to an overall annual health care cost of $\$ 7$ billion in the United States. ${ }^{4}$ Therefore, there is tremendous interest in the clinical community to investigate factors that alter the neurologic and functional outcomes of patients with acute SCI. ${ }^{5}$

Acute care for patients with SCI requires multifaceted management consisting of both medical and surgical interventions. The American Association of Neurological Surgeons (AANS) and Congress of Neurological Surgeons (CNS), the SCI Solutions Network, and the Consortium for Spinal Cord Medicine (CSCM) have published guidelines on the acute medical and surgical management of SCI. ${ }^{6-9}$ A subset of these recommendations supported maintenance of the mean arterial pressure (MAP) between 85 and $90 \mathrm{~mm} \mathrm{Hg}$ postinjury. Clinical evidence underlying this recommendation is derived from noncontrolled case series in which MAP was aggressively maintained $\geqslant 85 \mathrm{~mm} \mathrm{Hg}$ for $5-7$ days post-SCI. ${ }^{10-12}$ A more recent publication by Hawryluk et al. suggested that a greater proportion of patients with
SCI and associated neurologic improvement was noted, when MAP was maintained for an average reading above $85 \mathrm{~mm} \mathrm{Hg}{ }^{13}$

Human and animal studies suggest that early surgical decompression in acute cervical and thoraco-lumbar cord injuries improves neurologic outcome and aids recovery. ${ }^{1,14-19}$ The most commonly used definitions of early surgery were either within 24 or $72 \mathrm{~h}$ postinjury. ${ }^{17,19-24}$

In this study, we aim to evaluate the role of such medical and surgical interventions in improving the clinical outcomes in SCI. This study provides description of the natural history of neurologic recovery in different SCI subtypes and highlights the impact of early surgical decompression (within 24h) and maintenance of MAP $\geqslant 85 \mathrm{~mm} \mathrm{Hg}$ on neurologic outcome.

\section{METHODS}

Study sample

All trauma patients in the province of Nova Scotia with an injury severity score (ISS) $>12$ are prospectively identified through hospital admission records and entered into a centrally administrated registry. Queen Elizabeth II Health Sciences Center in Halifax represents level I trauma center for the province of Nova Scotia and receives all cases of traumatic SCI from different emergency departments across the province. Using the centralized trauma database, 
we identified patients coded as traumatic SCI presenting between 2006 and 2010. A retrospective chart review was then completed.

\section{Timing to surgery and blood pressure parameters}

Time to operative intervention was defined as the time between the initial call from the site of injury to emergency medical services (EMS) and the time of entering the operating room. In keeping with the evolving literature regarding the timing of surgical intervention, ${ }^{14,20}$ we defined 'early' surgical decompression as surgery within $24 \mathrm{~h}$ postinjury and 'late' surgery being past $24 \mathrm{~h}$.

Preoperative hypotension was defined as a single-documented systolic blood pressure of $<90 \mathrm{~mm} \mathrm{Hg}$, as described in the literature. ${ }^{6}$ Hourly MAP measurements are routinely recorded in the ICU by cardiovascular telemetry using a pressure transducer connected to an arterial line. The ICU in our institution utilizes norepinephrine, as first line agent in the maintenance of hypertensive targets. This practice is derived from evidence extrapolated from a randomized controlled trial illustrating the lower frequency of adverse effects associated with norepinephrine, as compared with dopamine in the treatment of shock. ${ }^{13}$ To rigorously examine the importance of MAP, we defined suboptimal MAP as measurements $<85 \mathrm{~mm} \mathrm{Hg}$ persisting constantly for $>2$ consecutive hours during the 5 -day period postinjury. The $85 \mathrm{~mm} \mathrm{Hg}$ cut-off is derived from a previous study by Vale and colleagues ${ }^{10}$ arbitrarily targeting MAP $>85 \mathrm{~mm} \mathrm{Hg}$ in patients with SCI, reasoning that this MAP goal was the upper limit of normal for uninjured middle aged males. This also forms the basis of the clinical guidelines recommendation in respect to MAP support postinjury. ${ }^{10-12}$

\section{Neurologic outcome and follow-up}

The American Spinal Injury Association (ASIA) Impairment Scale (AIS) is a standardized neurologic assessment commonly used to define the extent and severity of SCI. ${ }^{25-27}$ AIS assessments were performed at the initial admission to hospital, discharge from acute care, discharge from neurorehabilitation, and at

\section{Table 1 Demographic details of patients with $\mathrm{SCI}$}

\begin{tabular}{lc}
\hline Number of patients & 94 \\
Age range (y) & $16-94$ \\
Mean age \pm s.d. (y) & $47.6 \pm 20.7$ \\
Gender: Male:Female N (\%) & $74: 20(79: 21)$ \\
& \\
Mechanism of Injury (\%) & \\
MVC & $26(28)$ \\
ATV & $11(12)$ \\
Fall & $45(48)$ \\
Other & $12(13)$ \\
& \\
AIS grade (\%) & \\
A & $31(33)$ \\
B & $12(13)$ \\
C & $16(17)$ \\
D & $29(31)$ \\
NA & $6(6)$ \\
Mean AMS \pm s.d. (range) & $44.9 \pm 28.2(0-99)$ \\
Mean ASS \pm s.d. (range) & $109.47 \pm 56.6(24-224)$ \\
Severity of injury N (\%) & \\
Complete injury & \\
Incomplete injury & $31(33)$ \\
NA & $61(65)$ \\
Site of cord injury N (\%) & $2(2)$ \\
Cervical cord & \\
Thoraco-lumbar cord & $66(70)$ \\
\hline
\end{tabular}

Abbreviations: AIS, ASIA impairment scale; AMS, ASIA motor score; ASS, ASIA sensory score; ATV, all-terrain vehicle; MAP, mean arterial, pressure; MVC, motor vehicle collision; NA, not available. follow-up after discharge from neurorehabilitation. Neurological improvement was defined as a change in AIS of $\geqslant 1$. Total ASIA motor score (AMS) represents the summation of motor scores derived from the AIS assessment, and correlates strongly with walking ability. ${ }^{28}$ It was available from AIS assessments at initial admission and at discharge from acute care, with improvement in total AMS is defined as the difference between the two scores. When unavailable, AIS grades were derived based on documented neurologic examinations, including the key muscle groups that correspond to the ASIA levels and assessment of rectal tone, deep anal sensation, and sacral sensory sparing. Independent from the surgical team, the neurologic outcome (represented by all AIS assessment post-treatment) was evaluated by neurorehabilitation specialists.

\section{Statistical analysis}

Data analysis was performed using SPSS version 21.0. Results were either summarized as single proportions or as means with s.d. Differences of proportions of cases with SCI in study comparisons were assessed with the Pearson chi-squared test. For normally distributed data, two-sample student's $t$-test for independent samples. Alternatively, the Mann-Whitney $U$ test was used. All levels of significance were two-tailed and set at $P<0.05$.

\section{RESULTS}

\section{Descriptive data}

A total of 164 cases with suspected SCI were identified. After excluding 6 deaths and 64 cases that were inappropriately coded as having SCI $(n=62)$ or having incomplete medical records $(n=2), 94$ patients were included in the analysis. Table 1 provides SCI demographic features.

About $69 \%$ of patients were initially evaluated in an intermediate institution, which was associated with a significantly longer time-to-neurosurgical assessment when compared with patients directly transported to the trauma center $(11.7 \mathrm{~h} \pm 15.2$ vs $2.2 \mathrm{~h} \pm 2.7, \quad P<0.001)$. Although prolonged transport through an intermediate institution was also associated with a greater time to surgical decompression compared to patients transported directly to the trauma center $((88.4 \pm 158.2 \mathrm{~h})$ vs $(63.9 \pm 76.6 \mathrm{~h}))$, this difference was statistically insignificant $(P=0.85)$.

\section{Neurologic recovery in SCI}

AIS assessments were performed at means $26.7 \pm 19.5$ days (at discharge from acute care), $115.0 \pm 69.3$ days (at discharge from neurorehabilitation), and $252.0 \pm 152.8$ days (at follow-up post-neurorehabilitation). During these follow-up periods, AIS grades were available for 61,48 , and 47 patients, respectively. The overall improvement rate in the AIS grade at means 26.7, 115 and 252 days postinjury was $20 \%, 31 \%$, and $32 \%$, respectively. About $21 \%$ of patients presenting with AIS grade A improved to other grades (B and C) at mean 26.7 days, whereas $40 \%$ and $33 \%$ of patients with AIS grades $\mathrm{B}$ and $\mathrm{C}$, respectively, improved by $\geqslant 1$ grades. Although the difference in recovery rates between cervical and thoraco-lumbar cord injuries was not significant $(P>0.05)$, patients with cervical cord injuries demonstrated higher rates of neurologic improvement compared with patients with thoraco-lumbar cord injury, which was sustained at means 26.7, 115.0, and 252.0 days. Of note, AIS grade A cervical cord injuries demonstrate a higher rate of improvement at mean 252.0 days (31\%), when compared with thoraco-lumbar cord injuries with grade A (9\%). Among patients with thoraco-lumbar cord injury, about $91 \%$ of cases with AIS grade A demonstrated no improvement at mean 26.7 days postinjury, with lack of significant improvement sustained at mean 252.0 days, compared with AIS grades $\mathrm{B}$ and $\mathrm{C}$, all of whom improved by at least 1 grade at mean 252.0 days (Table 2). 
Table 2 Ordinal AIS grade changes at mean follow-ups 26.7, 115, and 252 days (rows), compared with initial AIS grade at presentation (column)

Overall study sample

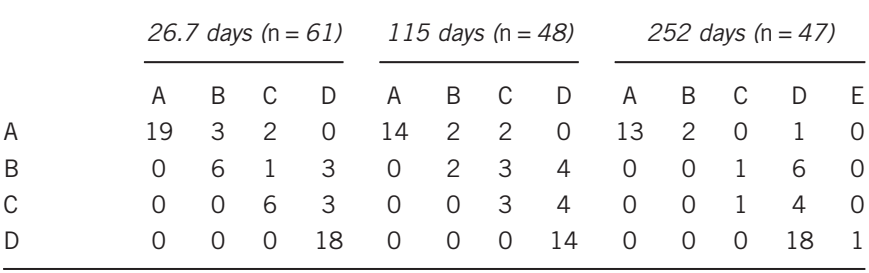

Cervical cord injuries

\begin{tabular}{|c|c|c|c|c|c|c|c|c|c|c|c|c|c|}
\hline & \multicolumn{4}{|c|}{26.7 days $(n=39)$} & \multicolumn{4}{|c|}{115 days $(n=31)$} & \multicolumn{5}{|c|}{252 days $(\mathrm{n}=31)$} \\
\hline & $A$ & $B$ & C & $\mathrm{D}$ & $A$ & B & C & $D$ & $A$ & B & C & D & $E$ \\
\hline A & 9 & 3 & 1 & 0 & 7 & 2 & 1 & 0 & 7 & 2 & 0 & 0 & 0 \\
\hline B & 0 & 4 & 0 & 2 & 0 & 0 & 3 & 2 & 0 & 0 & 1 & 3 & 0 \\
\hline C & 0 & 0 & 4 & 3 & 0 & 0 & 2 & 3 & 0 & 0 & 1 & 3 & 0 \\
\hline D & 0 & 0 & 0 & 13 & 0 & 0 & 0 & 11 & 0 & 0 & 0 & 13 & 1 \\
\hline
\end{tabular}

Thoraco-lumbar cord injuries

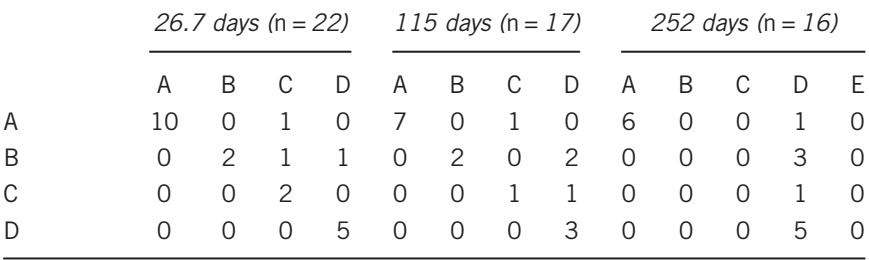

\section{Timing to surgical decompression}

Surgical decompression was performed in 75 patients as opposed to 19 patients treated non-surgically. Of those who did not receive surgical decompression, $37 \%(n=7)$ were identified as having central cord syndrome. Data on the timing to surgical decompression were available in 56 cases, with 23 patients treated within $24 \mathrm{~h}$ (early decompression), and 33 patients after $24 \mathrm{~h}$ (late decompression). The average time from injury to surgical decompression was $13.4 \pm 5.0 \mathrm{~h}$ (range, 5.6-20.9) and $127.7 \pm 165.4(24.1-212.5) \mathrm{h}$ for the early and late groups, respectively. The proportion of patients with complete cord injury was equally distributed between the early (40.9\%) and late $(40.6 \%)$ surgery groups. Comparing all cases with SCI in the early and late surgery groups, there was no statistically significant difference in the rate of AIS grade improvement at means 26.7 (26.3 vs $16.7 \%$, respectively, $P=0.44$ ) and 115.0 days (35.7 vs $27.8 \%$, respectively, $P=0.63)$. However, at mean 252.0 days, $47 \%$ of patients with SCI (including cervical and thoraco-lumbar cord injuries) in the early surgery group demonstrated significant improvement in AIS grade, compared with $13 \%$ of patients in the late surgery group $\left(X^{2}=4.7\right.$, $P=0.031)$. In cervical SCI, including both complete and incomplete injuries, subgroup analysis showed that $60 \%$ of patients in the early surgery group improved $\geqslant 1$ AIS grades at mean 252.0 days, compared with $20 \%$ in the late surgery group $\left(X^{2}=3.3, P=0.06\right)$. Similarly, higher proportions of patients with cervical SCI in the early surgical group demonstrated improvement at 26.7 (33 vs 27\%) and 115.0 days (50 vs $39 \%)$, although differences were not significant $(P=0.7$ and $P=0.6$, respectively). The proportion of complete injuries was equally distributed between the early and late surgery groups in cervical SCI ((33\%) vs $(29 \%)$, respectively, $P=0.76)$.

In thoraco-lumbar cord injuries, the early surgery group included 7 patients compared with 9 patients in the late group. At mean 27.7 days postinjury, the AIS grade improved in only $14 \%(n=1)$ with early surgery compared with none in the late surgery group $(P=0.2)$. The rate of improvement increased to $29 \%(n=2)$ in the early surgery group at mean 252 days with no improvement in the late surgery group $(P=0.15)$.

\section{Cardiovascular management}

Approximately $47 \%$ of all patients with SCI in our cohort were admitted to the intensive care unit, and $98 \%$ of these patients had serial MAP recordings. MAP measurement was performed in $84 \%$ and $36 \%$ of complete and incomplete SCI, respectively. In patients without MAP monitoring, $50 \%$ had AIS grade D on admission. Among those patients with serial MAP measurement, $82 \%(n=41)$ failed to meet the MAP goal of not $<85 \mathrm{~mm} \mathrm{Hg}$ for over any 2-h period during the 5-day duration post-SCI (Table 3). Failure to meet the targeted MAP goal was associated with lack of improvement in the AIS grade at mean 26.7 days postinjury, compared with patients with MAP $\geqslant 85 \mathrm{~mm} \mathrm{Hg}$. Among patients with MAP $<85 \mathrm{~mm} \mathrm{Hg}, 89 \%$ failed to demonstrate improvement in the AIS grade at mean 26.7 days, compared with $43 \%$ with MAP $\geqslant 85 \mathrm{~mm} \mathrm{Hg}(P=0.006$, Fisher's Exact $P=0.018$ ). The odds ratio for no neurologic improvement at mean 26.7 days in patients with MAP $<85 \mathrm{~mm} \mathrm{Hg}$ was 11.1 (95\% CI, 1.6-75.6) with a relative risk of 2.1 (95\% CI, 1.1-6.0).

The rate of mean total AMS improvement at mean 26.7 days postinjury was significantly higher in patients with SCI with MAP $\geqslant 85 \mathrm{~mm} \mathrm{Hg}$, compared with patients with MAP $<85 \mathrm{~mm} \mathrm{Hg}$ $((22.5 \pm 30.9)$ vs $(3.1 \pm 23.2)$, respectively, $P=0.048)$. Although there was no significant difference between the two MAP groups at later follow-up periods, a higher total AMS persisted in patients with MAP $\geqslant 85 \mathrm{~mm} \mathrm{Hg}$ (Table 3).

In subgroup analysis of patients with cervical SCI, the difference in neurologic outcome between the two MAP groups was also prominent, with $83 \%$ of patients with cervical SCI failing to show AIS grade improvement when associated with $\mathrm{MAP}<85 \mathrm{~mm} \mathrm{Hg}$, compared with $12 \%$ of cases with MAP sustained at $\geqslant 85 \mathrm{~mm} \mathrm{Hg}$. However, this difference did not reach our threshold for significance $(P=0.051$; OR 7.5, CI 95\% 0.9-66.1).

When allowing for interaction between $\mathrm{MAP}<85 \mathrm{~mm} \mathrm{Hg}$ and other variables including age, early surgery, and an initial systolic blood pressure $<90 \mathrm{~mm} \mathrm{Hg}$, a similar observation was encountered with $\mathrm{MAP}<85 \mathrm{~mm} \mathrm{Hg}$ being significantly associated with lack of neurologic improvement at average 26.7 days $(\mathrm{OR}=0.045,95 \% \mathrm{CI}$, $0.01-0.78, P=0.033)$, but not at 115.0 and 252.0 days. In this multivariate analysis, age, early surgery, and an initial systolic blood pressure $<90 \mathrm{~mm} \mathrm{Hg}$ were not significantly associated with AIS grade improvement $(P>0.05)$.

\section{DISCUSSION}

\section{Natural history of SCI}

We found that about one in five patients with SCI and AIS grade A improved into grade B or C at mean 26.7 days. Our series reflects a higher rate of AIS grade A improvement (21\%), compared with the improvement rate of $10-15 \%$ previously reported in the literature. ${ }^{4}$ In addition, one in three patients with complete cervical injuries improved, whereas only one in eleven with complete thoraco-lumbar SCI cases improved. Only one in fourteen patients with cervical AIS grade $\mathrm{D}$ converted to grade $\mathrm{E}$ at mean 252.0 days, indicating that 
Table 3 Neurologic outcome in patients with different MAP parameters 5 days postinjury or surgical decompression

\begin{tabular}{|c|c|c|}
\hline & \multicolumn{2}{|c|}{ MAP status } \\
\hline & $<85 \mathrm{~mm} \mathrm{Hg} \mathrm{n}=41$ & $\geqslant 85 \mathrm{~mm} \mathrm{Hg} \mathrm{n}=9$ \\
\hline \multicolumn{3}{|l|}{ Severity of $\mathrm{SCl}$} \\
\hline Complete $N$ & 22 & 4 \\
\hline NA $N$ & 1 & 1 \\
\hline \multicolumn{3}{|l|}{ Timing of surgery } \\
\hline Early & 15 & 4 \\
\hline \multicolumn{3}{|l|}{ Pre-hospital SBP } \\
\hline$<90 \mathrm{~mm} \mathrm{Hg} \mathrm{N}$ & 7 & 2 \\
\hline \multicolumn{3}{|c|}{ Lack of neurologic improvement in $\mathrm{SCl} \%$ (n) } \\
\hline At $26.7 \mathrm{~d}(n=35)$ & $89 \%(25 / 28)$ & $43 \%(3 / 7)$ \\
\hline At $115 \mathrm{~d}(n=27)$ & $73 \%(16 / 22)$ & $40 \%(2 / 5)$ \\
\hline At $252 \mathrm{~d}(n=25)$ & $71 \%(15 / 21)$ & $25 \%(1 / 4)$ \\
\hline \multicolumn{3}{|c|}{ Total AMS improvement in all cases mean \pm s.d. (n) } \\
\hline At $26.7 \mathrm{~d}(n=26)$ & $3.1 \pm 23.2(22)$ & $22.5 \pm 30.9(4)$ \\
\hline At $115 \mathrm{~d}(n=21)$ & $2.7 \pm 11.0(17)$ & $7.8 \pm 26.7(4)$ \\
\hline At $252 \mathrm{~d}(n=13)$ & $15.5 \pm 21.6(12)$ & $42.0 \pm(1)$ \\
\hline \multicolumn{3}{|c|}{ Lack of neurologic improvement incervical SCI } \\
\hline At $26.7 \mathrm{~d}(n=23)$ & $83 \%(15 / 18)$ & $40 \%(2 / 5)$ \\
\hline At $115 \mathrm{~d}(n=17)$ & $54 \%(7 / 13)$ & $50 \%(2 / 4)$ \\
\hline At $252 \mathrm{~d}(n=15)$ & $58 \%(7 / 12)$ & $33 \%(1 / 3)$ \\
\hline
\end{tabular}

Abbreviations: AMS, ASIA motor score; MAP, mean arterial pressure; NA, not available.

patients with AIS grade D rarely improve to baseline (that is, AIS grade E). Our data also demonstrate a high recovery rate in patients with SCI and AIS grade B: $100 \%$ of these patients converted to AIS grades $\mathrm{C}$ or $\mathrm{D}$, which is in keeping with previous reports of a significant recovery of substantial motor strength in patients with sacral sparing (that is, AIS grade B). ${ }^{29,30}$

\section{Timing of surgery}

The recent Surgical Timing in Acute Spinal Cord Injury Study (STASCIS) study demonstrated significant improvement in the AIS grades of patients with traumatic SCI after 'early' surgical decompression ( $24 \mathrm{~h}$ of injury). ${ }^{20}$ About $20 \%$ of patients treated early showed 2 or more AIS grade improvements, compared with $9 \%$ in the late surgery group $(\mathrm{OR}=2.6,95 \% \mathrm{CI}: 1.1-6.0)$. Factors that could contribute to late surgical decompression include delayed transportation to level I trauma centre. Our findings suggest that patients assessed at an intermediate institution were fivefold delayed in their arrival to trauma centre. Early surgery $(<24 \mathrm{~h})$ was significantly associated with a higher rate of neurologic improvement in SCI, compared with late surgery $(\geqslant 24 \mathrm{~h}) \quad(47$ vs $13 \%$, respectively). Interestingly, this difference was statistically significant only at mean 252 days postinjury, which is consistent with the results of STASCIS demonstrating increased rate of neurologic improvement at mean 4 months, and suggests that neurologic improvement as a result of early surgery might be more prominent at $\geqslant 4-6$ months postinjury.

\section{Cardiovascular management}

Augmentation of MAP in the initial management of SCI has been recommended by the AANS/CNS, the SCI Solution Networks, and the
CSCM. $^{6-9,31,32}$ The first investigation to suggest an effect of MAP on outcome was by Levi and colleagues, ${ }^{11}$ utilizing intravenous fluids, dopamine, and dobutamine to maintain MAP $>90 \mathrm{~mm} \mathrm{Hg}$ in 50 patients with acute cervical SCI. The authors included cases with complete SCI, as well as severe hemodynamic deficits (defined by pulmonary and systematic vascular resistance), which were found to have worse neurological outcomes. However, they were unable to account for the potential confounding effect of late surgical decompression and severe SCI, which could account for worse neurologic outcomes. Vale and colleagues ${ }^{10}$ administered fluids, dopamine, and norepinephrine to maintain an arbitrarily selected MAP $>85 \mathrm{~mm} \mathrm{Hg}$ for an average of 7 days, reasoning that this MAP goal was the upper limit of normal for uninjured males aging between 15 and 30 years. The authors reported high rates of neurologic recovery and suggested a role of increased MAP in improved neurologic outcomes. The duration of hypertensive treatment in the literature is variable, as two studies instituted a 7-day treatment duration, ${ }^{10,11}$ whereas one study maintained hypertensive treatment for 5 days postinjury. ${ }^{12}$ This time window was chosen on the basis of traumatic spinal cord studies suggesting that spinal cord edema peaks between 3 and 5 days, ${ }^{33}$ which prompted us to retrospectively evaluate the MAP measurements in this study within 5 days postinjury.

Hawryluk and colleagues retrospectively identified 100 patients with SCI, with MAP data and neurologic outcomes being available in 71 patients. ${ }^{13}$ The study sample was divided into three outcome groups including patients with no neurologic improvement $(n=35)$, patients with 1 AIS grade improvement $(n=23)$ and patients with $>1$ AIS grade improvement $(n=13)$. During the 5 -day period postinjury and whilst targeting a MAP of at least $85 \mathrm{~mm} \mathrm{Hg}$, all three groups were found to have an average MAP $>85 \mathrm{~mm} \mathrm{Hg}$. However, patients lacking neurologic improvement had a higher proportion of MAP values below $85 \mathrm{~mm} \mathrm{Hg}$. There was a high proportion of patients with AIS grade $\mathrm{A}$ in the no-improvement group (23 out of 35 patients, $66 \%$ ), which was statistically greater than patients improving by 1 AIS grade and $>1$ AIS grades with complete injuries constituting $13 \%$ and $23 \%$ of these groups, respectively. The authors excluded patients with AIS grade A $(n=29)$, demonstrating similar results but without accounting for the higher proportion of patients with AIS grade D $(48 \%)$ in the group improving by 1 AIS grade $(P=0.016)$. Exclusion of complete injuries from outcome analysis resulted in the reduction of sample size down to 45 patients subdivided into the three outcome groups. Our study suffers similar limitations in relation to a small sample size and smaller numbers of patients available for comparison in different MAP groups, which represents one of the limitations of retrospective studies

Inotrope-driven hypertensive treatment post-SCI is not entirely benign. According to one multi-centre randomized study of patients with shock, dopamine was significantly associated with a higher rate of arrhythmic complications compared to norepinephrine. ${ }^{34}$ However, few studies described dopamine and phenylephrine as the most commonly used first-line agents in SCI with adverse events including ventricular tachycardia occurring in about two-thirds of patients. ${ }^{35-37}$ Our study demonstrated that SCI cases failing to meet the foregoing MAP goals were 11 times less likely to exhibit neurologic recovery (defined as AIS grade $\geqslant 1$ ), which was independent of confounding factors such as the severity of SCI and late surgical decompression. Patients with MAP $\geqslant 85 \mathrm{~mm} \mathrm{Hg}$ had a statistically significant seven-fold improvement in their total AMS, compared with patients with MAP $<85 \mathrm{~mm} \mathrm{Hg}$. The difference in AIS grade was significant only at 1 month postinjury; although the difference in outcomes was not significant at subsequent follow-up (mean 115 and 252 days), 
there was a higher rate of lack of neurologic improvement in SCI cases with $\mathrm{MAP}<85 \mathrm{~mm} \mathrm{Hg}$. These data suggest that neurologic recovery maybe associated with hypertensive treatment post-SCI, regardless of the severity of SCI or timing of surgical decompression. In addition, these results are based on a strict definition of MAP being no less than $85 \mathrm{~mm} \mathrm{Hg}$ for any 2-h period over 5 days post-SCI. A randomized controlled trial is currently randomizing patients into two groups of MAP maintained $\geqslant 85 \mathrm{~mm} \mathrm{Hg}$ for 7 days postinjury using inotropes or MAP $\geqslant 65 \mathrm{~mm} \mathrm{Hg}$. The results are expected to shed light on whether normotensive blood pressure targets are noninferior to current clinical practice of induced hypertension.

\section{Study limitations}

This study suffers from small numbers available for assessment of clinical outcomes that generally reflect the shortcomings of retrospective studies encountered by other investigators. ${ }^{13}$ Furthermore, we stress that the reader should interpret these data critically, as patients either lost for follow-up or at incomplete follow-up can not be inferred to have done better or worse than the population we presented. This potential source of bias calls for cautious interpretation of the results and signals the need for randomized controlled trials. Furthermore, AIS grade assessment in $48-72 \mathrm{~h}$ postinjury has been shown to be a predictor of neurological recovery. ${ }^{5-7}$ However, these data were not available in retrospect, which poses an important limitation in assessing neurological recovery in this cohort but also represented a critical area in which the standards of care on our institution have been impacted significantly after this review. We also found retrospectively that MAP augmentation period was 2 days shorter than clinical guidelines recommendation (7 days), which highlights the value of auditing clinical practice in order to ensure successful implementation of clinical guidelines. Since this review, we instituted changes in our facility to include strict monitoring of MAP and extension of treatment duration to 7 days. The $85 \mathrm{~mm} \mathrm{Hg}$ cut-off is arbitrary and derived from a study by $\mathrm{Vale}^{10}$ targeting MAP $>85 \mathrm{~mm} \mathrm{Hg}$, reasoning that this was the upper limit of normal. Although we recognize that such cut-off is not based on strong evidence, it also forms the basis of the clinical guidelines recommendation. ${ }^{10-12}$

\section{CONCLUSION}

This study suggests that early surgical decompression can be associated with improved neurologic outcome in SCI, emphasizing the role of urgent transportation in achieving timely surgical decompression. These data also support the hypothesis that maintaining a MAP $\geqslant 85 \mathrm{~mm} \mathrm{Hg}$ maybe associated with higher rates of neurologic recovery at mean 26.7 days, with no statistical significance at prolonged follow-up periods although a higher rate of neurological recovery persisted in patients with $\mathrm{MAP} \geqslant 85 \mathrm{~mm} \mathrm{Hg}$. Indeed, a small sample size and considering the nature of a retrospective review represent a common challenge to research this area and call for multicentre prospective registries or randomized controlled trials.

\section{DATA ARCHIVING}

There were no data to deposit.

\section{CONFLICT OF INTEREST}

The authors declare no conflict of interest.

\section{ACKNOWLEDGEMENTS}

The efforts of the Nova Scotia Trauma Registry team are much appreciated in facilitating allocation of patients and acquisition of clinical data.
1 Fehlings MG, Arvin B. The timing of surgery in patients with central spinal cord injury. J Neurosurg Spine 2009; 10: 1-2.

2 Pirouzmand F. Epidemiological trends of spine and spinal cord injuries in the largest Canadian adult trauma center from 1986 to 2006. J Neurosurg Spine 2010; 12: 131-140.

3 DeVivo MJ. Causes and costs of spinal cord injury in the United States. Spinal Cord 1997: 35 809-813.

4 McDonald JW, Sadowsky C. Spinal-cord injury. Lancet 2002; 359: 417-425.

5 Al-Habib AF, Attabib N, Ball J, Bajammal S, Casha S, Hurlbert RJ. Clinical predictors of recovery after blunt spinal cord trauma: systematic review. J Neurotrauma 2011; 28: 1431-1443

6 Ryken TC, Hurlbert RJ, Hadley MN, Aarabi B, Dhall SS, Gelb DE et al. The acute cardiopulmonary management of patients with cervical spinal cord injuries. Neurosurgery 2013; 72(Suppl 2): 84-92.

7 Hadley MN, Walters BC, Grabb PA, Oyesiku NM, Przybylski GJ, Resnick DK et al. Guidelines for the management of acute cervical spine and spinal cord injuries. Clin Neurosurg 2002; 49: 407-498.

8 Walters BC, Hadley MN, Hurlbert RJ, Aarabi B, Dhall SS, Gelb DE et al. Guidelines for the management of acute cervical spine and spinal cord injuries: 2013 update. Neurosurgery 2013; 60(Suppl 1): 82-91.

9 Consortium for Spinal Cord M. Early acute management in adults with spinal cord injury: a clinical practice guideline for health-care professionals. J Spinal Cord Med 2008; 31: 403-479.

10 Vale FL, Burns J, Jackson AB, Hadley MN. Combined medical and surgical treatment after acute spinal cord injury: results of a prospective pilot study to assess the merits of aggressive medical resuscitation and blood pressure management. J Neurosurg 1997; 87: 239-246.

11 Levi L, Wolf A, Belzberg H. Hemodynamic parameters in patients with acute cervical cord trauma: description, intervention, and prediction of outcome. Neurosurgery 1993; 33: 1007-1016.

12 Wolf A, Levi L, Mirvis S, Ragheb J, Huhn S, Rigamonti D et al. Operative management of bilateral facet dislocation. J Neurosurg 1991; 75: 883-890.

13 Hawryluk G, Whetstone W, Saigal R, Ferguson A, Talbott J, Bresnahan J et al. Mean arterial blood pressure correlates with neurological recovery after human spinal cord injury: analysis of high frequency physiologic data. J Neurotrauma 2015; 32: 1958-1967.

14 Furlan JC, Noonan V, Cadotte DW, Fehlings MG. Timing of decompressive surgery of spinal cord after traumatic spinal cord injury: an evidence-based examination of pre-clinical and clinical studies. J Neurotrauma 2011; 28: 1371-1399.

15 Fehlings MG, Perrin RG. The timing of surgical intervention in the treatment of spinal cord injury: a systematic review of recent clinical evidence. Spine 2006; 31(Suppl 11): S28-S35.

16 Cengiz SL, Kalkan E, Bayir A, llik K, Basefer A. Timing of thoracolomber spine stabilization in trauma patients; impact on neurological outcome and clinical course. A real prospective (rct) randomized controlled study. Arch Orthop Trauma Surg 2008; 128: 959-966.

17 Krengel WF 3rd, Anderson PA, Henley MB. Early stabilization and decompression for incomplete paraplegia due to a thoracic-level spinal cord injury. Spine 1993; 18: 2080-2087.

18 Carlson GD, Minato Y, Okada A, Gorden CD, Warden KE, Barbeau JM et al. Early time- dependent decompression for spinal cord injury: vascular mechanisms of recovery. J Neurotrauma 1997; 14: 951-962.

19 Delamarter RB, Sherman J, Carr JB. Pathophysiology of spinal cord injury. Recovery after immediate and delayed decompression. J Bone Joint Surg Am 1995; 77: 1042-1049

20 Fehlings MG, Vaccaro A, Wilson JR, Singh A, D WC, Harrop JS et al. Early versus delayed decompression for traumatic cervical spinal cord injury: results of the Surgical Timing in Acute Spinal Cord Injury Study (STASCIS). PLOS ONE 2012; 7: e32037.

21 Levi L, Wolf A, Rigamonti D, Ragheb J, Mirvis S, Robinson WL. Anterior decompression in cervical spine trauma: does the timing of surgery affect the outcome? Neurosurgery 1991; 29: 216-222.

22 Vaccaro AR, Daugherty RJ, Sheehan TP, Dante SJ, Cotler JM, Balderston RA et al. Neurologic outcome of early versus late surgery for cervical spinal cord injury. Spine 1997; 22: 2609-2613.

23 Mirza SK, Krengel WF 3rd, Chapman JR, Anderson PA, Bailey JC, Grady MS et al. Early versus delayed surgery for acute cervical spinal cord injury. Clin Orthop Relat Res 1999; 359: 104-114.

24 McKinley W, Meade MA, Kirshblum S, Barnard B. Outcomes of early surgical management versus late or no surgical intervention after acute spinal cord injury. Arch Phys Med Rehabil 2004; 85: 1818-1825.

25 Ditunno JF Jr, Young W, Donovan WH, Creasey G. The international standards booklet for neurological and functional classification of spinal cord injury. American Spinal Injury Association. Paraplegia 1994; 32: 70-80.

26 Waring WP 3rd, Biering-Sorensen F, Burns S, Donovan W, Graves D, Jha A et al. 2009 review and revisions of the international standards for the neurological classification of spinal cord injury. J Spinal Cord Med 2010; 33: 346-352.

27 Hadley MN, Walters BC, Aarabi B, Dhall SS, Gelb DE, Hurlbert RJ et al. Clinical assessment following acute cervical spinal cord injury. Neurosurgery 2013; 72(Suppl 2): 40-53. 
28 Waters RL, Adkins R, Yakura J, Vigil D. Prediction of ambulatory performance based on motor scores derived from standards of the American Spinal Injury Association. Arch Phys Med Rehabil 1994; 75: 756-760.

29 Marino RJ, Ditunno JF Jr, Donovan WH, Maynard F Jr. Neurologic recovery after traumatic spinal cord injury: data from the Model Spinal Cord Injury Systems. Arch Phys Med Rehabil 1999; 80: 1391-1396.

30 Katoh S, El Masry WS. Motor recovery of patients presenting with motor paralysis and sensory sparing following cervical spinal cord injuries. Paraplegia 1995; 33: 506-509.

31 Casha S, Christie S. A systematic review of intensive cardiopulmonary management after spinal cord injury. J Neurotrauma 2011; 28: 1479-1495.

32 Dvorak MF, Noonan VK, Fallah N, Fisher CG, Rivers CS, Ahn H et al. Minimizing errors in acute traumatic spinal cord injury trials by acknowledging the heterogeneity of spinal cord anatomy and injury severity: an observational Canadian cohort analysis. J Neurotrauma 2014; 31: 1540-1547.
33 Yashon D, Bingham WG Jr, Faddoul EM, Hunt WE. Edema of the spinal cord following experimental impact trauma. J Neurosurg 1973; 38: 693-697.

34 De Backer D, Biston P, Devriendt J, Madl C, Chochrad D, Aldecoa C et al. Comparison of dopamine and norepinephrine in the treatment of shock. N Engl J Med 2010; 362: 779-789.

35 Inoue T, Manley GT, Patel N, Whetstone WD. Medical and surgical management after spinal cord injury: vasopressor usage, early surgerys, and complications. J Neurotrauma 2014; 31: 284-291.

36 Ploumis A, Yadlapalli N, Fehlings MG, Kwon BK, Vaccaro AR. A systematic review of the evidence supporting a role for vasopressor support in acute SCI. Spinal Cord 2010; 48: 356-362

37 Readdy WJ, Whetstone WD, Ferguson AR, Talbott JF, Inoue T, Saigal R et al. Complications and outcomes of vasopressor usage in acute traumatic central cord syndrome. J Neurosurg Spine (e-pub ahead of print 31 July 2015; doi:10.3171/ 2015.2.SPINE14746) 